\title{
Review of Book: Handbook of Positive Youth Development: Advancing Research, Policy and Practice in Global Contexts (2021)
}

\section{Dimitrova, R. \& Wiium, N, Switzerland: Springer Nature. Editorial, 754 pages. ISBN: 978-3-030-70261-8}

\author{
Steven Eric Krauss ${ }^{1,2}$ (D)
}

Received: 17 May 2021 / Accepted: 24 May 2021 / Published online: 3 July 2021

(C) The International Society for Quality-of-Life Studies (ISQOLS) and Springer Nature B.V. 2021

Since the 1990s, positive youth development (PYD) has played a central role in shaping youth development practice and policy. As an initial response to America's over-dependence on "deficit-based" approaches to working with at-risk adolescents, the strengths-based approach of PYD has become mainstream practice in many countries throughout the world. In parallel with this growth in practice, PYD scholarship has steadily grown worldwide, as more evidence from the social and health sciences comes to the fore delineating the conditions and processes for developing optimal well-being, thriving and success among young people. Reasons for this explosion of interest include the operationalization of PYD as a workable approach to understanding pathways to successful social and individual youth well-being, including substantial psychological and health outcomes. Unfortunately, to date, the field has been deprived of a single volume that has attempted to capture this rich, global tapestry of burgeoning research and development.

As part of the Springer Series on Child and Family Studies, the Handbook of Positive Youth Development: Advancing Research, Policy and Practice in Global Contexts is a potentially ground-breaking work, comprising 37 chapters of PYD scholarship from 38 countries representing every major geographic region of the world (e.g., Europe, Asia, Africa, Middle East, Australia, New Zealand, and the Americas). The text provides a truly international perspective on the latest research in the field of PYD, featuring new scholarship from underrepresented and understudied geographic locations. The Handbook sets out to address three major gaps in the global PYD literature: the advancement of theoretical and empirical knowledge

Steven Eric Krauss

lateef@upm.edu.my

1 Institute for Social Science Studies, Universiti Putra Malaysia, 43400 Serdang, Selangor, Malaysia

2 Faculty of Educational Studies, Universiti Putra Malaysia, Serdang, Malaysia 
within a global context, considering more culturally-relevant applications of PYD; the refinement of methodological issues and measurement in under-researched contexts; and the integration of PYD scholarship with relevant research, policy, and practice, including the advancement of PYD from cross-disciplinary perspectives. As such, the volume attempts to pay full recognition to the ongoing need for contextualizing youth development scholarship within a broader system of human development. Scholarship from a wide range of disciplines is represented in the chapters including positive, developmental, cross-cultural, social and community psychology, well-being, child and family studies, education, prevention, intercultural relations, anthropology, sociology, methodology, counseling, emerging adulthood, intervention and implementation science.

The Handbook is segmented into two main parts, representative of the contributions the volume attempts to make in advancing global PYD scholarship, namely theory and practice. Part I-PYD in Global Contexts presents 17 chapters with new PYD conceptualizations (the 7Cs model) and research examples from India, Indonesia, Pakistan, Malaysia, China, Ghana, Colombia, Peru, Mexico, Belize, Brazil, Albania, Kosovo, Macedonia, Serbia, Turkey, Italy, Spain, Iceland, Norway, Australia, New Zealand, Bulgaria and Romania. Part II-PYD Applications and Interventions includes 18 chapters on applied PYD studies in diverse contexts including those from China, Colombia, Italy, Jordan, Kenya, the Philippines, Sweden, Thailand, Jamaica, South Africa, Slovenia, Lithuania, Finland, Norway, Canada and the United States. With this breadth of coverage, the Handbook makes a strong case for its main objective of championing and advancing more global voices, perspectives and impact, while promoting a new generation of PYD scholars in largely neglected contexts. While the sheer size of the text might seem overwhelming, one cannot be but impressed with the effort made to amass such a diverse, broad-base sampling of PYD research from so many parts of the world.

Part 1 of the Handbook begins with an introductory chapter by the volume's editors that situates the importance of the work within the broader PYD field. The introduction provides a poignant precursor to the chapters that follow, including the background aims, audience and vision for the work. The chapter emphasizes the growing importance of PYD around the globe, with a focus on holistic adolescent development, and heralds the important research that has been going on in many countries, often under the radar of mainstream publishing outlets. To give their work the attention it deserves, the editors - in collaboration with Springer - proposed the Handbook to bring the voices of global PYD research to the mainstream. In so doing, the editors set out to reach a "culturally-sensitive readership" by presenting high-quality, global-impact oriented scholarship within a single volume. In so doing, the Handbook aims to open up new avenues for replication and collaboration.

Part 1 comprises 18 chapters that deal mostly with underpinning theoretical and conceptual issues related to PYD in a global context. An interesting development of note in Part 1, captured by several of the chapters, is the application and extension of the 5 C's (Lerner, 1995) and subsequent 6 C's (Pittman et al., 2000) models of PYD to a new 7 C's formulation. In response to the growing need for creative problem-solving among young people in light of global challenges, the outcome of "creativity" has been added to the model. While youth in many countries around the 
globe struggle to adapt to an age of uncertainty brought on by COVID-19, withering public support for education and youth services, structural changes to labor markets and decreasing employment opportunities, social unrest and an increasing VUCA environment in general, creative problem-solving has become an important contributor to youth thriving (Diržytė et al., 2021). Creativity is closely tied to self-directed and self-determined learning (Hennis, 2017; Morris, 2020) as well as entrepreneurship (Erro-Garcés, 2020; Zampetakis et al., 2011), the latter of which has become a point of emphasis in many low- and middle-income country's youth-related policies. Part 1 also presents a rich array of research on the application of the developmental assets and 5/6/7 C models in understanding young people's development in the context of environmental issues, personality development, healthy lifestyle behaviors, happiness and well-being, family relations, student engagement and academic achievement, identity development, social support and gratitude, resilience, and future expectations. In line with the goal of the Handbook, the section concludes with a chapter extending research on PYD measurement by reporting on findings from a cross-national study testing the factorial structure and measurement invariance of the 5 C's in Bulgaria, Italy, Norway and Romania.

Building on the theoretical work from Part 1, Part 2 of the Handbook showcases the diversity in applied PYD research taking place across the globe. Part 2 presents 17 more chapters of PYD research including several cross-national studies, encompassing five broad PYD contexts: education and schooling, minority and at-risk youth, parenting and families, traditional youth programs, and youth development in the digital age. The introductory chapter in Part 2 highlights the increase in crossnational and cross-disciplinary studies in PYD, as well as the diversity in designs taking place across the globe. In so doing, the chapter references the Parenting Across Cultures project, a longitudinal collaboration among investigators from nine countries (China, Colombia, Italy, Jordan, Kenya, the Philippines, Sweden, Thailand, and the United States). Building on the landmark 10-year study, the chapter provides a landscape for international PYD research by presenting additional examples of international collaborative research, a summary of predictors of PYD from various cultural perspectives, salient measurement and methodological issues that in international collaborative research on PYD, and implications for future research, policy, and practice, including the potential for researchers in one country to learn from researchers in other countries.

In Part 2, the reader gets a profound sense of the role PYD is playing around the world in shaping the major ecological systems of youth development, and the need to better understand it. PYD is expanding from its initial U.S.-based focus on WEIRD (Western, Educated, Industrialized, Rich, and Democratic) youth populations. With this diversity, research is becoming more context-driven and inclusive. Part 2 of the Handbook illustrates this clearly through the breadth of research presented. From the effectiveness of a socio-emotional learning program in Slovenia to the intersection of PYD and classroom climate in Sweden, Part 2 presents several examples of how researchers are exploring the role of PYD in promoting thriving and inclusivity in schools around the world. In addition to schooling, Part 2 also illustrates ongoing research on PYD in traditional youth-serving programs such as scouting and leadership development in the U.S. and South Africa, respectively, 
as well as studies on PYD in the context of parent education and family support, in relation to vocational participation by young people. Several initiatives with marginalized and at-risk youth, including the use of a PYD approach to engage NEET youth in Jamaica, violent radicalization programs in Canada and engaging underserved youth in Miami, USA, illustrate the need to avoid the 'all-or-nothing' approach to PYD. While PYD's 'strengths-based' language is often construed as an approach that completely ignores deficits and avoidance of risks, Part 2 highlights the reality that in non-WEIRD contexts a fluid application of the principals and practices of PYD is required. In many countries, the extent of youth needs due to extreme poverty, social and economic injustice, war and political violence, and other environmental factors require holistic approaches to development (Catalano et al., 2002; Meyer \& Chetty, 2017). That is, in diverse settings there can be no single best approach. Applying a specific model or practice to a specific context must consider how an application will affect youth in that particular context, which might include both the promotion of thriving and reductions of deficit behaviors.

The final chapter provides a thematic summary of the contents of the Handbook. The authors put forward four major themes of the text: PYD as a systems-level perspective; the inclusion of both strength promotion and deficit reduction; there is no "best" model of PYD; and defining PYD requires specificity. In their summary of the research presented, the authors content that a high degree of specificity is needed when applying PYD-predicated research, policy and practice to global contexts. They proffer that while this may lead some to question the practicality of applying PYD perspectives, the evidence suggests that this is already taking place. As a result, there is much to be optimistic about for the future of PYD in a global context. A major contribution of the Handbook, therefore, is in presenting considerable evidence that PYD has begun to gain a foothold around the world in shaping youth development policy and practice. In this regard, the Handbook will undoubtedly serve as an important resource for a broad audience of youth researchers, practitioners and policy makers for many years to come.

\section{References}

Catalano, R. F., Hawkins, J. D., Berglund, M. L., Pollard, J. A., \& Arthur, M. W. (2002). Prevention science and positive youth development: Competitive or cooperative frameworks? Journal of Adolescent Health, 31(6), 230-239.

Diržytė, A., Kačerauskas, T., \& Perminas, A. (2021). Associations between happiness, attitudes towards creativity and self-reported creativity in Lithuanian youth sample. Thinking Skills and Creativity, $40,100826$.

Erro-Garcés, A. (2020). Creativity and emotions as drivers for social entrepreneurship. Journal of Social Entrepreneurship, 11(3), 300-316.

Hennis, T. (2017). Engaging at-risk youth through self-directed learning. Italian Journal of Educational Technology, 25(1), 18-30.

Lerner, R. M. (1995). America's youth in crisis. Sage Publications.

Meyer, L., \& Chetty, R. (2017). Violence in schools: A holistic approach to personal transformation of at-risk youth. Acta Criminologica: African Journal of Criminology \& Victimology, 30(3), 121-134.

Morris, T. H. (2020). Creativity through self-directed learning: Three distinct dimensions of teacher support. International Journal of Lifelong Education, 39(2), 168-178. 
Pittman, K., Irby, M., \& Ferber, T. (2000). Unfinished business: Further reflections on a decade of promoting youth development. The Forum for Youth Investment.

Zampetakis, L. A., Gotsi, M., Andriopoulos, C., \& Moustakis, V. (2011). Creativity and entrepreneurial intention in young people: Empirical insights from business school students. The International Journal of Entrepreneurship and Innovation, 12(3), 189-199.

Publisher's Note Springer Nature remains neutral with regard to jurisdictional claims in published maps and institutional affiliations. 